Article

\title{
Female Journalists' Experience of Online Harassment: A Case Study of Nepal
}

\author{
Samiksha Koirala \\ Department of Media and Communication Studies, Nepal Open University, 44700, Kathmandu; \\ E-Mail: sameexa@gmail.com
}

Submitted: 3 October 2019 | Accepted: 19 January 2020 | Published: 25 February 2020

\begin{abstract}
This study examines the experiences of female journalists in Nepal in the context of rapidly growing expansion of broadband Internet. By examining the findings of the qualitative in-depth interview of 48 female journalists, it argues that online platforms are threatening press freedom in Nepal, mainly by silencing female journalists. The study also indicates that the problem is particularly severe in such a patriarchal society as a significant number of incidents of abuse go unreported, largely due to a culture of shame as well as ineffective legislation. Over the course of this article, I have attempted to show how social issues raised by second-wave feminism and online feminism are similar. The findings show that some of the female journalists experiencing harassment tolerate it by being 'strong like a man,' while many of them avoid social media platforms such as Twitter and Facebook to keep free of such abuse. The study also suggests that individual efforts to tackle the vicious issue of misogyny might not be enough and collective effort from legislation, media organisations, and feminists is required to address the issue.
\end{abstract}

\section{Keywords}

female journalists; gender; harassment; journalism; Nepal; online harassment; online participation

Issue

This article is part of the issue "Rethinking the Safety of Journalists" edited by Kristin Skare Orgeret (Oslo Metropolitan University, Norway) and William Tayeebwa (University of Makerere, Uganda).

(C) 2020 by the author; licensee Cogitatio (Lisbon, Portugal). This article is licensed under a Creative Commons Attribution 4.0 International License (CC BY).

\section{Introduction: Online Misogyny and Women}

Digital media have become an important aspect of journalism. Journalists are using social media to find news sources, share news stories, and to engage with audiences. Feminist scholars have argued that digital platforms can help to bring women's concerns and feminist voices into the mainstream media (Baer, 2016; Carter Olson, 2016). However, there has also been an increase in rampant online misogyny (Ging \& Siapera, 2018; Reporters Without Borders, 2018). The term online harassment is synonymously used for other terminologies such as cyber-bullying, gender-trolling (Mantilla, 2013), and is defined as a practice where an individual or group use the Internet to harass, harm, or ridicule another person using either a fake or real identity.

Female journalists across the world are facing discrimination and harassment in the workplace and in pub- lic. In addition to existing barriers, personal attacks via online comments, threatening emails, and social media posts represent a serious threat to the participation of female journalists. Even in countries that are relatively safe for journalists, online misogyny is becoming the norm for many female journalists (Adams, 2018). While the Internet is an important tool for journalists to acquire and disseminate information, it is also being used for practices such as public shaming, cyberstalking, and intimidation, among others. Early feminist Internet scholars (Hayles, 1999; Plant, 1996) were optimistic about the digital platform's potential to surpass gender-based discrimination in interactions. However, it was quickly apparent that the online world was not resistant to discrimination or abuse. Various studies (Bartlett, Norrie, Patel, Rumpel, \& Wibberley, 2014; Nadim \& Fladmoe, 2019) show that online harassment has stronger effects on women than men. 
The digital platform has created a forum of free expression, contributing to a democratization of the public sphere (Ash, 2016). The Internet has also a unique opportunity to challenge the extent of male social dominance. However, various threats associated with technologies are silencing the diverse voices needed for a well-functioning democracy. Some studies (Harris, Mosdell, \& Griffiths, 2016; Henrichsen, Betz, \& Lisosky, 2015) contend that gendered assumptions are present even in cyberspace making it challenging to obtain gender equality.

As online interaction has been normalized as a part of journalists' routine in the age of digital journalism (Chen \& Pain, 2017), the Internet is also creating a new sphere in which female journalists are likely to face harassment. Many journalists are expected to have an online presence and converse with the public through social media, however, those conversations often become misogynistic (Chen \& Pain, 2017). It is also contended that online harassment has further increased with the emergence of social media such as Facebook, Instagram, and Twitter (Hackworth, 2018, p. 52). An analysis of reader comments within The Guardian newspaper's online content shows that articles written by female journalists received a higher proportion of hateful comments (blocked by moderators as a proxy for abuse and dismissive trolling; Gardiner, 2018).

A study by Demos, a think-tank in the United Kingdom, found that "journalism is the only category where women received more abuse than men, with female journalists receiving roughly three times as much abuse as their male counterparts" (Demos, 2014). Many female journalists today are experiencing harassment on the Internet because of their gender (Adams, 2018; South Asia Media Solidarity Network, 2016). Similarly, a poll of the International Women's Media Foundation (IWMF, 2014) found that two-thirds of respondents reported facing intimidation as well as violent and sexual threats online in response to their work.

Journalists should not have to work in fear due to their job or gender. However, resistance to female journalists in male-dominated industries such as the news media is not a new phenomenon. Feminist media researchers from all around the world have long emphasised the issue of female journalists' safety, particularly the issue of harassment in the workplace and in public (Joseph, 2005; Ross, 2004). The majority of recent studies have examined texts used in online abuse. However, there have been limited studies concerning online harassment and the experiences of female journalists. The studies are even more limited in the case of developing countries such as Nepal because Internet-related issues are often ignored as a 'first-world problem.' This study aims to examine Nepalese female journalists' experiences of online harassment, seeking to determine whether such cases of harassment are of a personal or professional nature. In addition, this research focuses on how such incidents impact the work experience of fe- male journalists (in terms of reporting and expressing their views online) and journalism as a whole.

\subsection{Background: The Nepali Context}

The Internet has become vital for journalists to do their job across the globe, and Nepal is no exception. Internet penetration which was less than 10 percent, around a decade ago has now reached more than 67 percent of Nepal's population as of August 2019 (Nepal Telecommunications Authority, 2019). Not only has the number of Nepalese online news portals reached 1,380 (Press Council of Nepal, 2018), journalism as a whole is moving into the digital space. It may be contended that the changes that have taken place in journalism practices make the issue of online harassment of journalists, mainly women, increasingly important.

The majority of journalists have access to broadband Internet, and while this has facilitated their day to day reporting, it can also make them vulnerable to online abuse. Nepal continues to face widespread genderbased discrimination and it is clear that these problems are being replicated online. Incidents of onlinebased crime have almost doubled in 2019 in Nepal, compared to the previous year, according to statistics of Metropolitan Police Division (2019, as cited in Manandhar, 2019).

Following the end of the decade long armed conflict in 2006, the number of women is rising in maledominated fields such as the military, politics, and journalism. According to the Federation of Nepali Journalists (2017), the number of female journalists has increased to 18 percent, from around five percent in 2005. Despite this, participation in and representation of women in journalism is such that it continues to be a masculine domain (Koirala, 2018). The point of departure of this article is that online harassment poses an additional threat to the participation of women in a male-dominated profession such as journalism. Although gender trolls may have individual motivations for harassment, Mantilla (2015) opines that widespread misogyny found on websites perpetuate a distinct form of violent gender abuse within Internet culture.

Despite the evidence, experiences of online harassment have not yet been studied in much detail. Although the scope of the study is limited to Nepal, it may be that the Nepali experience proves relevant in countries with a similar socio-cultural background. Various studies also show that gender and media matters reveal more commonalities than differences (Joseph, 2005; The World Association for Christian Communication, 2015).

\section{Theorising Gender, Media, and Technology}

To examine the experiences of online harassment, this article draws on the broader context of feminist theories, media, and technology. As presented above, problematic features of old media have transferred onto new 
media as well. Emma A. Jane (2016) contends that there is a similarity between contemporary gendered cyberhate and key social problems (namely rape, domestic violence, and workplace sexual harassment) addressed by second-wave feminists. It may be contended that gendered online harassment is a reflection of the cultural understanding of gender and women's inferior place in society. Gendered online hate is rooted in "old" misogynistic discourses that insist on women's inferiority to men (Jane, 2014).

Early feminist Internet researchers were deeply divided by the utopian or dystopian nature of online spaces. Many early studies of cyberfeminism tended to either demonize or celebrate the potential for online feminism (Schulte, 2011, p. 729). However, most of the feminist interventions into new media at present have always offered a way to balance the hyperbolic utopic and dystopic framings of technologies (Shaw, 2014, p. 1). However, much scholarship conceptualizes online abuse as something different from a real-world problem. In a country like Nepal, where the digital world is still a new phenomenon, harassment and abuse of the Internet fail to draw attention. The technologically deterministic approaches focus on the differences between online abuse and physical harassment due to the former's anonymity and the lack of accountability online; stressing the need to regulate online activities. I argue that what happens in the 'virtual world' is experienced in the real world by real people, making it a serious issue. Some scholars such as Megarry (2014, p. 47) stress the need for online harassment to be conceptualized as a practice which excludes women's voices from the (digital) public sphere. This brings us to the explanation of Shaw (2014, p. 2) who contends that similar to all racism and sexism, it arises from a position of privilege created via the same historical events that made "tech culture" a particular form of masculine culture. Similarly, a study by Dale Spender (1980, as cited in Adams, 2018, p. 4) has shown that abuse can result in exclusion from the public domain. It may also weaken democracy as women are prevented from exerting influence in the culture (Byerly \& Ross, 2006).

Various studies on gender and media show that women are still discriminated against and are denied fair representation (Byerly, 2016; Byerly \& Ross, 2006). There is a link between women's participation in a maledominated area such as journalism and the sexist abuse they encounter (Adams, 2018). British author Sadie Plant (1996) discusses how the "digital revolution" marks the decline of masculine hegemonic power structures, as the Internet is a non-linear world which cannot be ordered or controlled. Previous studies have shown that in any sphere, men fear a loss of power when women pushback a boundary for gender equality (Beard, 2014; Megarry, 2014, p. 48). Individual responsibility, ignoring the abuse, or even denying the truth that there is abuse, are some of the central themes discussed by women as they talk about their experience of online abuse (Ahmed,
2016; DiCaro, 2015). These responses illustrate the arguments of postfeminist media culture within which female journalists operate. Drawing from the post-feminist discourse, Rosalind Gill (2007) emphasises autonomy and free choice whereby women are "called on to selfmanage, self-discipline." These discourses of individualism diminish gender politics as various forms of discrimination are "framed in exclusively personal terms in a way that turns the idea of the personal-as-political on its head" (Gill, 2007, p. 153). Similarly, in the early 1960s, rape, domestic violence, and workplace sexual harassment were trivialized and mocked, often being regarded as a personal matter (Citron, 2014, p. 22).

The gender hierarchy poses a difficult problem for female voices which goes beyond the public/private divide. Speaking in public is considered to be deviant to the traditional role of women and various studies have shown that women who do not conform to their traditional gender roles are disproportionately targeted for harassment (Megarry, 2014, p. 49).

I argue that gender-based harassment is intended to reinforce the patriarchy, where women are expected to be a submissive victim. Despite the similarities between online and offline misogyny, its anonymous nature and its potential to rapidly travel to a vast audience make tackling online harassment a greater challenge (Gagliardone, Gal, Alves, \& Martinez, 2015). I contend that there is a need to address the new theoretical challenges raised by the digital age in feminist scholarship.

Drawing from various feminist media theories, I argue that hegemonic masculinity allows men to maintain hierarchical status over women as men continue to rule the world of news media. The concept of hegemonic masculinity has been used in feminist media studies to explain men's power over women. The theory also has been used to explain men's use of violence to legitimize traditional gender hierarchies. I contend that online harassment can also be considered as a form of violence to suppress female journalists. Feminists also contend that sexual harassment (online or offline) are a result of a deeply entrenched patriarchal gender system that discriminates against women and favours "a dominant normative form of masculinity" (Uggen \& Blackstone, 2004, p. 66). While the study attempts to examine the findings of the study in relation to more than one strand of feminism, it relies heavily on the argument of secondwave feminism. Drawing from the arguments of secondwave feminism it may be contended that individual experiences of online harassment are linked to sexist power structures, meaning the 'personal is political.' While there is a growing body of work exploring online harassment, there remains limited empirical or theoretical insight into the impact of such harassment. The analysis presented here focuses on the nature of the harassment and its impacts. This will allow me to further explore how the experience of abuse intersects with aspects of gender equality, press freedom, and identity politics. 


\section{Methods}

This research is feminist in nature as it mainly focuses on the experiences of women's harassment. A topic often marginalized in academic research. As a former journalist, I was curious to examine what was the nature and impact of online harassment on women's professional and personal lives. I have employed qualitative analysis to explore the following research questions: 1 ) What is the nature of online harassment as experienced by female journalists in Nepal? 2) How has it impacted their personal and professional lives? 3) What strategies are being adopted to combat the issue? Qualitative in-depth interviews were carried out with some of the analyses being enriched by my previous experience of working as a journalist in Nepal. The interviews were semi-structuredwe followed an interview guide in order to get answers to the same questions from all interviewees, while also being able to adapt to the particularities of each interview.

\subsection{Qualitative In-Depth Interview}

Qualitative in-depth interview is one of the traditional forms of data collection. One of the main advantages of this method is it maximises data quality while minimising nonresponses. In-depth interviews are often used to seek information in highly sensitive projects (Lavrakas, 2008). While 26 interviews were conducted by the author personally, the remaining 22 were conducted with the help of a research assistant. The research assistant joined me for around ten interviews to become familiar with the approach and focus of the interview. All the interviews were recorded and transcribed later. A research assistant also helped me in the process of transcribing the interviews. 48 female journalists based in two major Nepalese cities-Kathmandu and Pokharaparticipated in this study. Most of the female journalists identified themselves as news reporters and few as editors or news coordinators. Majority of the reporters were working with political and business departments. The respondents included representatives of 12 different Nepalese media institutions, including online, television, radio, and print.

Before adopting the interview as the method of this study, I attempted to conduct an online survey of around 120 journalists. The initial aim of this research was to reach the widest possible range of journalists. While few of the respondents returned the questionnaires, many of them were reluctant to participate even with a monthlong deadline. This was not surprising given the busy nature of newsrooms and the sensitive topic in a comparatively rigid culture. Only 22 journalists filled in the form after several follow-ups. I used the findings of the online survey to further refine my interview questions. Otherwise, the findings solely rely on the in-depth interviews of the 48 journalists. The survey was also important to identify potential participants for the interview. It helped me in the process of purposive sampling.
While the survey could have been more representative, I had to go with personal in-depth interviews which may have self-selection bias. As the objective of the study is not simply to quantify the problem but also to contribute to on-going efforts in combating the issue of online harassment, I opine that the study has benefitted from the method of a qualitative in-depth interview with semi-structured questionnaires. Despite the obvious fact of selection-bias, in the second attempt, I went for the in-depth qualitative interview with purposive sampling. As it only covers only four percent $(n=48)$ of the country's total number of female journalists, the findings should be treated with caution. This research does not claim that it is representative of the industry as a whole. However, it aims to offer a deeper insight into female journalists' responses to abuse.

This study aims to examine the experiences of female journalists faced with online harassment and to assess how it has affected them and the news industry. While harassment was not measured in absolute terms, journalists' own assessment (never, sometimes, often) was used. Subjects were divided into age groups of 21-25, $26-30,31-35,36$ and above. Of these, the larger number were in the 21-25 age group. The questionnaire had nine multiple-choice questions with the option to comment (in some questions) with four of them being open-ended. In cases where the subject reported not having been harassed four questions were skipped meaning they were asked only nine questions. The duration of the interview was 20 to 45 minutes and was conducted mostly in their offices, colleges (in case of those who were also studying in universities), or in coffee shops on a few occasions. The interviews took place between 20th February and 18th August 2019. All the participants were asked the same series of questions, with follow-up questions. While participants from various types of media organizations are included in the survey, only two cities, Kathmandu and Pokhara, were included due to time and resource limitations.

\section{Findings and Discussion}

These interviews with female journalists largely confirmed what had been found by previous studies - that female journalists face harassment and abuse mainly due to their work and gender. Adding to previous studies which have been based mainly in the first world, most of these incidents were not reported in light of there being a lack of proper policy as well as other cultural factors.

Respondents were asked if they have ever faced any sort of online harassment. As many as 67 percent $(n=32)$ said that they have experienced some sort of abuse online. Only four percent $(n=2)$ said that they had experienced the abuse repeatedly. Participants could choose the options: never, sometimes, or often. The higher number of victims may be mainly because of the countryspecific factor as journalism is considered a masculine profession with more than 80 percent of the workforce 
being male. The findings indicate that the widespread inequality and discrimination against women which remains in Nepali society is increasingly being replicated online (Koirala, 2019). Also, part of the problem is that Nepali culture largely sees men's sexism as something innate rather than deviant. Eve teasing, sexists jokes, and even domestic violence are culturally accepted in the physical world (Koirala, 2018). Consequently, sexism is deemed 'normal' and the sexist behaviours and comments continue even in the digital world.

Comparison between age groups shows that women in the 21-25 age group are more likely to report having received harassment than their older colleagues. The findings show that 82 percent $(n=18)$ of female journalists in this group have experienced sexual and non-sexual insults or threats online compared to only 50 percent $(n=2)$ of women journalist above 35 . The findings coincide with the results of other studies (Everbach, 2018) that younger female journalists are most likely to face harassment. While the harassment is experienced by the participants of all age groups, McLaughlin, Uggen, and Blackstone (2012, as cited in North, 2016, p. 8) argue that women in higher positions are frequently harassed compared to women in a subordinate position. However, the findings of this study suggest that journalists in junior positions (74 percent, $n=28$ ) are more likely to face abuse online than their senior counterparts (44 percent, $n=4)$. These findings may be partly justified with the data of the age group which also suggests that younger female journalists are more likely to be harassed. The data, however, contradict the hypothesis of McLaughlin, Uggen, and Blackstone.

Similarly, comparisons between the types of news media organization showed another pattern of harassment. The data indicate that female journalists working with online news portals ( 90 percent, $n=10$ ) and television (80 percent, $n=12$ ) were more likely to face harassment compared to those working in radio (50 percent, $\mathrm{n}=6$ ) and newspaper journalism (37 percent, $\mathrm{n}=3$ ). This may be partly due to the nature of their work, which keeps them online more frequently and makes them easily identifiable by the audience compared to journalists from radio and print media.

\subsection{Nature of Harassment}

The other question asked was what sort of harassment the female journalists encountered. Respondents were allowed to select more than one option if needed. Out of 32 who responded to this question 20 journalists (62 percent) stated that the harassment was sexist in nature which involved comments about physical attributes and gender. On the nature of harassment, 48 percent of respondents $(n=15)$ stated that the harassment was sexual in nature. They reported having received rape threats, nude photos, and other harassment of a sexual nature online. The studies (Kaur, 2012; Robinson, 2005) on gender and harassment indicate the use of sexual harass- ment/violence is considered a legitimate and expected means to reaffirm that the public and private positions of hegemonic masculinity which exist in the physical world also exist in the online world.

Although this study did not include the experience of male reporters, the gendered and sexual nature of harassment indicates female journalists are more likely to experience abuse than their male colleagues. Women face sexual harassment more often than men, irrespective of their profession. Studies show that most of the harassment towards men occur in the form of name-calling and attempts to embarrass; however, for women, the most common forms of harassment were sexual in nature (Stroud \& Cox, 2018, p. 293). Seven of the respondents (22 percent) also stated that they had also faced physical threats online. Two of them were rape threats and the other five featured abduction and physical attacks.

Drawing from feminist media theories, I argue that hegemonic masculinity maintains that women don't belong in public spheres such as news media, and this study confirms that barriers continue to prevent female journalists, from being as accepted as their male counterparts. One of the senior reporters of a daily business newspaper stated:

We have a long way to go in creating equality in our society and gendered treatment inside news media organisations and sexist comments of the audience is just a part of it....Our society still expects us to see in traditional roles...cooking, taking care of the home. (Interviewee, 17 February, 2019)

\subsection{The Platform of Online Abuse}

Respondents were also asked where (on which online platform) they faced harassment. Out of 32 who responded to this question, 20 individuals singled out personal messaging apps and 18 identified social networking sites. Five respondents said that Email was the platform for harassment whereas only two mentioned online news comments. A large number of female journalists are facing harassment via personal messaging apps such as Viber and Whatsapp. It suggests that most of the harassment is private in nature. Studies (Adams, 2018; Usher, Holcomb, \& Littman, 2018) of the western world indicate that harassment was more common in the form of trolling and public posts. The findings of the interview suggest that such practices were less frequent in Nepal's case. Nevertheless, some of the journalists acknowledged that they have faced nasty comments in public posts. While the Nepali news media have started moderating online comments, news stories shared on social media platforms continue to receive hateful comments, mostly misogynistic.

Journalism is Nepal is largely dominated by men. Female journalists in Nepal face various forms of discrimination regarding their salaries and promotion prospects (Koirala, 2018, p. 225). It is worrying that more than 
two-thirds of female journalists face harassment online. Worse still, most of this harassment is sexual in nature and hardly reported. Participation of female journalists in Nepal is limited to 18 percent of the workforce (Federation of Nepali Journalists, 2017). Men always have dominated journalism and when women enter this sphere, they challenge men's power and control (Everbach, 2018). Online harassment might be one of the ways to resist women's entry into journalism.

\subsection{Offenders of Online Harassment}

The next question of the interview tried to identify who the perpetrators were. Unlike the findings of other studies (Adams, 2018; IWMF, 2014) which suggest a larger number of offenders tend to be male colleagues/bosses, only 15 percent $(n=5)$ of the online-based abuse was committed by their male colleagues or males in a senior position. More than 62 percent $(n=20)$ of the abuse was from someone who could not be identified. Around 22 percent $(n=7)$ of the respondents stated that the harassment was from news sources or people they knew on a personal level. Three respondents also stated that they had been asked for sexual favours in exchange for a news story via email and Facebook messenger. One of the respondents stated that the person was a senior officer at the ministry: "He was not direct but the implied meaning of the email was what will I get in exchange for this news story. Can you and I go somewhere quiet and romantic for a drink to discuss it [the information for news] further," she quoted him as saying (personal communication). Ammu Joseph's (2005) research with female journalists also found that character assassination, touching, and demands for sexual favours were some of the types of harassment reported by the female journalists. While the medium for harassment has changed over time, the findings indicate that male news sources feel entitled to sexual favours in exchange for news stories.

The study shows that most of the harassment was coming from anonymous users and 18 percent of the online harassment incidents were from male colleagues. One of the participants stated that in most of the instances harassment had come from an unidentified account and she never bothered to find the perpetrator. She said:

If I had tried to find out the offender, maybe I could.... I just wanted to forget the incident and move forward...I thought I would be devastated if I find out the offender was someone I know at a personal level. (personal communication)

The findings indicate that the anonymity provided by the Internet gives perpetrators greater courage to humiliate their victims. Most of their interactions take place in public spaces, surrounded by many people, whereas in online conversation they find the 'privacy' which they lack in their offices.

\subsection{Influence of Online Harassment}

Studies have shown that experiences with online harassment can incite fear and other emotional symptoms. It is argued that it can also lead individuals to become more cautious in expressing their views (Gelber \& McNamara, 2016; Nadim \& Fladmoe, 2016) and silence journalists (Henrichsen et al., 2015). I contend that online harassment of women is a form of sex discrimination that may cause short-term as well as long-term harm. It is meant to silence and humiliate women who try to enter male-dominated spaces (Barak, 2005; Vitis \& Gilmour, 2017). To examine the influence of online harassment, the respondents were asked how the harassment impacted their personal and professional lives. The majority of the respondents who received abusive messages reported that it had a significant impact on them. Most of the respondents who received harassment repeatedly stated that they found the experience 'traumatic.' One of them (television presenter/reporter) discussed how the repeated incidents were discouraging her from continuing in the profession:

I have encountered repeated harassment about my looks and physical attributes from unknown people online..... One of them was also a rape threat....The comments can be so vulgar that I am hesitant to share the details...this makes me very conscious about myself.... struggle to concentrate on my reporting and find myself discouraged. (Interviewee, February 20, 2019)

A political reporter shared her experience of being a target from an opponent party while reporting a news story concerning 'shut-down protest.' Because of the repeated incidents of similar harassment, she stated that she was considering changing career shortly. She said:

I received several messages on my Facebook and Twitter, most of them in the form of private messages. It included physical threats and some of the comments were also sexist in nature.... am so frustrated that I want to leave this profession. (Interviewee, July 22,2019 )

Five of the respondents said that they considered changing their career at some point after facing harassment. This is particularly alarming given that participation of female journalists is already low in Nepal. With an increasing number of media houses, there is tough competition for opportunities. However, female journalists argue that the work environment is not 'women-friendly' and the experiences of the online world are adding to their woes. One of the Pokhara based news reporters highlighted how repeated sexist comments were an additional burden to bear on top of her high workload:

I've tried my best not to let cyber-bullying impact my news reporting but there are many occasions when 
I feel discouraged....While I know my job has been so easy because of the Internet...online experience is just adding problems to our already challenging profession. (Interviewee, July 22, 2019)

While the trolling and bullying online was usually from people they did not know or from fake accounts, respondents had also received such abuse from someone within their circle. One of the radio correspondents in her late twenties says:

Harassment makes it uncomfortable to cover a specific area if your harasser is your news source.... know it was an important news story but I simply dropped the story as covering it meant to reach the same person [offender] time and again. I have experienced harassment in a face to face interview too but it just gets nastier and unbearable when it is online. The harassment is more indirect in physical communication...they [news sources] imply certain things like they want 'something' in exchange for news...it is not very direct. (Interviewee, February 21, 2019)

The majority (60 percent, $n=19$ ) of the female journalists who have faced harassment said that they have limited their online activities or been more cautious while sharing or posting something on social media platforms. Three of them reported abstaining from controversial topics while two of them dropped a news story, following an incident of online harassment.

The comments reveal that the abuse was affecting their opinion and journalistic content. Participants reported that they avoided particular topics such as women rights, feminism, and corruption to 'save' them from the possible bullying. Most of the participants stated that they were practising "self-censorship" in terms of content and style. One of the reporters also said that she prefers being anonymous in controversial stories.

One of the senior reporters of a Pokhara based local newspaper states:

There are times, I write, post, edit, and post and delete. As I report on issues related to gender, my posts and news stories seem too angry many people....Because of the repeated incidents of intimidation online as well as offline, I prefer to limit my online presence, particularly on Facebook and Twitter....Most of the time they [offenders] attempt to shut us down in the name of "saving our culture." (Interviewee, July 22, 2019)

\subsection{Combating Online Harassment}

This study also examines the mechanisms used by female journalists to curb such abuse. Emma A. Jane (2016, p. 2) suggests that combating online harassment requires a combination of individualism as well as collectivismin what could be described as a hybrid of second- and third-wave approaches. The third-wave of feminism began in the 1990s as a backlash against the second-wave of feminism and began to apply feminist theory to a wider variety of women in terms of colour, sexuality, and other characteristics. Some of the popular strategies have been around hashtag campaigns such as \#Metoo and \#Everydaysexism. However, most of the strategies shared by the participants were more individual in nature. This indicates that there is a lack of solidarity when it comes to the issue of harassment. Nevertheless, the findings show that the female journalists with greater experience were more aware of the need to report the issue and also had developed strategies on dealing with the abuse. Respondents were asked: What strategies do you (as a woman journalist) use to avoid/minimize incidents of harassment online or to help you deal with the abuse? Participants were allowed to pick more than one option and were asked to add additional strategies if they had one.

Out of the 32 responses received, 20 (62 percent) mentioned ignoring the abuse. The majority of them suggested that they had to develop a 'thick skin' to cope with the harassment. One of the online news reporters pointed out that the major strategy was to be strong hearted like a man. She went on to say that although online abuse was unacceptable the easiest way seemed to be just to ignore as if it had never happened (personal communication). This indicates that some of the journalists are adapting to become "one of the boys" (MelinHiggins, 2004, p. 199); embracing this strategy and rejecting their female gender to fit in with the masculine normative is highly likely to impact news production by reducing the diversity of voices.

Only two of the respondents said that she informed her employer so that they might take action. Likewise, 14 (44 percent) of them also mentioned that they had deactivated their accounts or had kept offline for a time. Being forced to stay away from the Internet means their voices were silenced.

Three of the respondents said that they had discussed the issue in the forum of female journalists or amongst themselves. None of them mentioned reporting it to the police. It may be mainly because offenders continue to enjoy impunity in the absence of any strict laws relating to cyber-harassment or the male-dominant culture of the news media which allows perpetrators to operate freely.

Two of the respondents also reported the abuse to Facebook. This indicates that at least some female journalists are aware of how to seek help from online platforms to stay safe. The other questions were included to examine how news media organisations were addressing this issue.

Respondents were asked if they thought their organisation was helping them (and their colleagues) to cope with cyber harassment. Only four out of 48 respondents stated that they were positive about their organisations' approach against harassment online as well as offline. The majority of them expressed doubt that their media 
house was equipped to deal with such issues.

One of the respondents working in an online news portal said:

Nobody has ever talked about it [any sort of harassment]. We [female journalists] still hesitate to report it to our boss if we are harassed physically. So, reporting online harassment might be ridiculed. Many of us are not even sure what extent of harassment is bearable and what should be reported....Organisational policies on such issues would have helped but we don't have one that deals with cyber-attacks. (Interviewee, February 26, 2019)

Only one of the respondents reported having stayed on the sidelines while reporting a news story on domestic violence. Three other of the 32 respondents stated they had dropped a news report or avoided reporting on a particular issue due to their fear of abuse. Quantitatively, the number might not seem huge. However, these findings show a trend where harassment is influencing women on a professional and emotional level with increasing numbers of female journalists limiting their activities online as a coping mechanism against harassment. The underreporting of online harassment suggests that 'the culture of shame' and the apparent hegemonic masculinity is forcing female journalists to remain quiet. The victimblaming culture is another aspect of Nepali society which results in many victims, including those in journalism, preferring not to disclose such incidents.

The findings suggest that female reporters are remaining silent for fear of being shrugged off by their seniors. Female journalists are making conscious decisions to maintain low profiles and steer clear of issues likely to ignite cyberbullying. Based on this study, female journalists have mostly been bullied via social media-mainly Facebook-possibly to its status as one of the preferred social media platforms.

Most of the respondents stated that they were trying to curb the issue of harassment on a personal level. I argue that there are no personal solutions to this. Only collective action can bring about a permanent reduction in, if not an end, to gender-based harassment. Following the "Me Too movement" (a large movement against sexual harassment and assault in which media began reporting widespread harassment by powerful male figures), the potential of social media to strengthen the reach of women's activism by bringing women's concerns to the mainstream media (Carter Olson, 2016) is being explored. However, in Nepal's context, there is still a long way to go as journalists who are responsible for exposing such issues are shying away from reporting the issue of their own harassment.

\section{Conclusion}

This article shows that female journalists are being subject to online abuse, forcing many of them to be silenced.
The experiences of female journalists indicate that the Internet sustains sexist abuse, objectification of women, and male hegemony. For most of the women who participated in the research, abuse actually worsened due to their work in the news media industry. The online abuse is not only negatively affecting women's lives, but also their journalism. I contend that if women's voices are excluded (or silenced) due to online harassment, it becomes a threat not only to the exercise of free speech but also to the functioning of democracy itself (Nadim \& Fladmoe, 2019, p. 12). The research indicates that online harassment is forcing women to be marginalised from the media industry (Byerly \& Ross, 2006, p. 231).

The article has demonstrated that online harassment is making female journalists cautious when expressing their opinions. The findings also indicate that female journalists keep these incidents private which partly explains why Nepali society is unaware of this issue's prevalence. The plurality of voices is one of the key indicators of a democratic society. During the decade-long conflict, the safety of journalists was at a record low due to deaths, disappearances, and a number of physical attacks. While the safety situation has improved since the end of the armed conflict, the experience stated above poses serious questions regarding the safety of journalists and press freedom in Nepal.

Online harassment may have numerous consequences including psychological, financial, and even physical. As the findings indicate, after facing online abuse, journalists become cautious for their own safety, forced to self-censor, or stop reporting entirely, and even change their profession. Globally, there is an increased demand for digital safety to curb incidents of such abuse, however, at present, few tools are available to help journalists. In Nepal's context, as the study indicates, the majority of journalists lack the basic knowledge to create a safe digital space.

According to the respondents, news organisations in Nepal lack policies on digital security or even against harassment. Besides law enforcement and adequate laws against digital harassment, journalistic training to promote awareness of the tools and strategies to cope with harassment are also likely to be important. Similarly, feminist interventions-crucial in combating online harassment-have largely been absent in Nepal's case. As a result, there was no solidarity in the efforts against harassment with most choosing an individual strategy for a common problem.

The findings presented here should encourage more research into the gendered nature of online harassment. More detailed studies are necessary to examine the impacts of such harassment. I have situated the issue of online harassment particularly concerning the 'second-wave of feminism' which presents women as a homogenous group whose interests are represented by a single politics. While there are some advantages to representing women as a single group, it may be challenging to address the issues of misogyny in cyberspace. 
While the focus of the study is on gendered harassment, it has ignored the experiences of women of particular castes, religions, as well as other categories. Future studies should include the experiences of female journalists from particular racial groups, castes, ethnic groups, or religions for an adequate exploration of online harassment. Theoretically, future research may benefit from broader arguments of feminism beyond the identity politics approach.

\section{Acknowledgments}

I would like to offer my great appreciation to all the participants of the interviews. I would also like to thank Trishna Acharya for assisting during my data collection.

\section{Conflict of Interests}

The author declares no conflict of interests.

\section{References}

Adams, C. (2018). "They go for gender first." The nature and effect of sexist abuse of female technology journalists. Journalism Practice, 12(7), 850-858.

Ahmed, N. (2016). Discussing about sexual harassment (breaking silence). The role of technology. In Proceedings of the $2016 \mathrm{CHI}$ conference extended abstracts on human factors in computing systems (pp. 459-472). New York, NY: Association for Computing Machinery.

Ash, T. G. (2016). Free speech. Ten principles for a connected world. London: Atlantic Books.

Baer, H. (2016). Redoing feminism: Digital activism, body politics, and neoliberalism. Feminist Media Studies, 16(1), 17-34.

Barak, A. (2005). Sexual harassment on the Internet. Social Science Computer Review, 23(1), 77-92.

Bartlett, J., Norrie, R., Patel, S., Rumpel, R., \& Wibberley, S. (2014). Misogyny on Twitter. London: Demos. Retrieved from http://demos.co.uk/files/MISOGYNY_ ON_TWITTER.pdf

Beard, M. (2014). The public voice of women. London Review of Books, 36(6), 11-14.

Byerly, C. M. (Ed.). (2016). The Palgrave international handbook of women and journalism. Berlin: Springer.

Byerly, C. M., \& Ross, K. (2006). Women and media: A critical introduction. Hoboken: John Wiley \& Sons.

Carter Olson, C. (2016). \#BringBackOurGirls: digital communities supporting real-world change and influencing mainstream media agendas. Feminist Media Studies, 16(5), 772-787.

Chen, G. M., \& Pain, P. (2017). Normalizing online comments. Journalism Practice, 11(7), 876-892.

Citron, D. K. (2014). Hate crimes in cyberspace. Cambridge, MA: Harvard University Press.

Demos (2014). Demos: Male celebrities receive more abuse on Twitter than women. Retrieved from https://demos.co.uk/press-release/demos-malecelebrities-receive-more-abuse-on-twitter-thanwomen-2/

Ging, D., \& Siapera, E. (2018). Special issue on online misogyny. Feminist Media Studies, 18(4), 515-524. https://doi.org/10.1080/14680777.2018.1447345

DiCaro, J. (2015, September 27). Threats, vitriol, hate. Ugly truth about women in sports and social media. Sports Ilustrated. Retrieved from https://www.si. com/cauldron/2015/09/27/twitter-threats-vileremarks-women-sports-journalists

Everbach, T. (2018). "I realized it was about them...not me": Women sports journalists and harassment. In J. R. Vickerty \& T. Everbach (Eds.), Mediating misogyny (pp. 131-149). Cham: Palgrave Macmillan.

Federation of Nepali Journalists. (2017). Members. Retrieved from http://www.fnjnepal.org/en/page/ members

Gagliardone, I., Gal, D., Alves, T., \& Martinez, G. (2015). Countering online hate speech. Paris: UNESCO Publishing.

Gardiner, B. (2018). "It's a terrible way to go to work": What 70 million readers' comments on the Guardian revealed about hostility to women and minorities online. Feminist Media Studies, 18(4). https://doi.org/ 10.1080/14680777.2018.1447334

Gelber, K., \& McNamara, L. (2016). Evidencing the harms of hate speech. Social Identities, 22(3), 324-341.

Gill, R. (2007). Postfeminist media culture: Elements of a sensibility. European Journal of Cultural Studies, 10(2), 147-166.

Hackworth, L. (2018). Limitations of "just gender": The need for an intersectional reframing of online harassment discourse and research. In J. R. Vickerty \& T. Everbach (Eds.), Mediating misogyny (pp. 51-70). Cham: Palgrave Macmillan.

Harris, J., Mosdell, N., \& Griffiths, J. (2016). Gender, risk and journalism. Journalism Practice, 10(7), 902-916.

Hayles, N. K. (1999). The condition of virtuality. In P. Lunenfeld (Ed.), The digital dialectic: New essays on new media (pp. 68-95). Cambridge, MA: MIT Press.

Henrichsen, J. R., Betz, M., \& Lisosky, J. M. (2015). Building digital safety for journalism: A survey of selected issues. UNESCO Publishing.

International Women's Media Foundation. (2014). Violence and harassment against women in the news media: A global picture. International Women's Media Foundation. Retrieved from www.iwmf.org/ our-research/journalist-safety

Jane, E. A. (2014). "You're an ugly, whorish, slut." Feminist Media Studies, 14, 531-546. https://doi.org/ 10.1080/14680777.2012.741073

Jane, E. A. (2016). Online misogyny and feminist digilantism. Continuum, 30(3), 284-297.

Joseph, A. (2005). Making News: Women in Journalism. New Delhi: Penguin Books India.

Kaur, S. (2012). The necessity for a sexual harrasment act in Malaysia. IIUM Law Journal, 17(2). https://doi.org/ 
10.31436/iiumlj.v17i2.39

Koirala, S. (2018). Gender representations in the Nepali press during pre-conflict, conflict and post-conflict periods (Unpublished Doctoral Dissertation). Oslo: University of Oslo.

Koirala, S. (2019, April 8). Online sexism: Challenges of tackling it. The Himalayan Times. Retrieved from https://thehimalayantimes.com/opinion/onlinesexism-challenges-of-tackling-it/

Lavrakas, P. J. (2008). Encyclopedia of survey research methods. London: Sage.

Mantilla, K. (2013). Gendertrolling: Misogyny adapts to new media. Feminist Studies, 39(2), 563-570.

Manandhar, A. (2019). Cruel and curious online sexual harassment cases in Nepali cyberspace. The Annapurna Express. Retrieved from https://theannapurna express.com/news/cruel-and-curious-online-sexualharassment-cases-in-nepali-cyberspace-1838

Mantilla, K. (2015). Gendertrolling: How misogyny went viral. Santa Barbara, CA: ABC-CLIO.

Megarry, J. (2014). Online incivility or sexual harassment? Conceptualising women's experiences in the digital age. In Women's studies international forum (Vol. 47, pp. 46-55). Oxford: Pergamon.

Melin-Higgins, M. (2004). Coping with journalism: Gendered newsroom culture. In M. de Bruin \& K. Ross (Eds.), Gender and newsroom cultures; identities at work (pp. 197-222). Cresskill, NJ: Hampton Press.

Nadim, M., \& Fladmoe, A. (2016). Research on the nature and extent of hate speech (Hate speech, report 1). Oslo: Norwegian Institute for Social Research.

Nadim, M., \& Fladmoe, A. (2019). Silencing women? Gender and online harassment. Social Science Computer Review. https://doi.org/10.1177/089443 9319865518

Nepal Telecommunications Authority. (2019). MIS report. Kathmandu: Nepal Telecommunications Authority. https://nta.gov.np/wp-content/uploads/ MIS-2076-Shrawan.pdf

North, L. (2016). Damaging and daunting: Female journalists' experiences of sexual harassment in the newsroom. Feminist Media Studies, 16(3), 495-510.

Plant, S. (1996). On the matrix: Cyberfeminist simulations. In R. Shields (Ed.), Cultures of internet: Virtual spaces, real histories, living bodies (pp. 170-183).
London: Sage Publications.

Reporters without Borders. (2018). RSF index 2018: Hatred of journalism threatens democracies. Paris: Reporters without Borders.

Robinson, K. H. (2005). Reinforcing hegemonic masculinities through sexual harassment: Issues of identity, power and popularity in secondary schools. Gender and Education, 17(1), 19-37.

Ross, K. (2004). Sex at work: Gender politics and newsroom culture. In M. de Bruin \& K. Ross (Eds.), Gender and newsroom cultures: Identities at work (pp. 145-162). Cresskill, NJ: Hampton Press.

Schulte, S. R. (2011). Surfing feminism's online wave: The Internet and the future of feminism. Feminist Studies, 37(3), 727-744.

Shaw, A. (2014). The Internet is full of jerks, because the world is full of jerks: What feminist theory teaches us about the Internet. Communication and Critical/Cultural Studies, 11(3), 273-277.

South Asia Media Solidarity Network. (2016). South Asia media solidarity bulletin: October, 2016. Retrieved from https://www.ifj.org/media-centre/ news/detail/category/asia-pacific/article/southasia-media-solidarity-bulletin-january-1.html

Stroud, S. R., \& Cox, W. (2018). The varieties of feminist counterspeech in the misogynistic online world. In J. R. Vickerty \& T. Everbach (Eds.), Mediating Misogyny (pp. 293-310). Cham: Palgrave Macmillan.

The World Association for Christian Communication. (2015). Global media monitoring project. Who makes the news? Retrieved from http://whomakesthenews. org/gmmp/gmmp-reports/gmmp-2015-reports

Uggen, C., \& Blackstone, A. (2004). Sexual harassment as a gendered expression of power. American Sociological Review, 69(1), 64-92.

Usher, N., Holcomb, J., \& Littman, J. (2018). Twitter makes it worse: Political journalists, gendered echo chambers, and the amplification of gender bias. The International Journal of Press/Politics, 23(3), 324-344.

Vitis, L., \& Gilmour, F. (2017). Dick pics on blast: A woman's resistance to online sexual harassment using humour, art and Instagram. Crime, Media, Culture, 13(3), 335-355.

\section{About the Author}

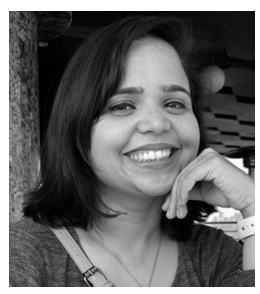

Samiksha Koirala is a Teaching Faculty and Subject Committee Member at Nepal Open University. She is also pursuing her postdoctoral research funded by NORHED project. She earned her PhD in Journalism from the University of Oslo, Norway. Koirala has more than eight years of experience in broadcast and print journalism. Her research interests include gender and journalism, media representations, and the safety of journalists. 